Journal of Social Sciences 6 (1): 33-40, 2010

ISSN 1549-3652

(C) 2010 Science Publications

\title{
On Studying the Linkage between Children Mortality, Prosperity and Education Using Fully Latent Models
}

\author{
${ }^{1}$ Faisal G. Khamis and ${ }^{2}$ Muna F. Hanoon \\ ${ }^{1}$ Department of Finance and Banking, \\ ${ }^{2}$ Department of Management Information Systems, \\ Faculty of Economics and Administrative Sciences, \\ Al-Zaytoonah University of Jordan, Amman, Jordan
}

\begin{abstract}
Problem statement: Many studies were carried out in many countries to examine the relationship between children mortality, prosperity and education. These studies are useful for the purpose of intervention and policy making. Questions were raised about the problem of children mortality which is still not recognized well in most developing countries because of different techniques were used in the analysis of previous studies and also there are different circumstances in different countries. Approach: The objective is to examine the relationship between children mortality, prosperity and education to create a clear picture of health status of three indicators of children mortality: stillbirth, neonatal and infant. Several techniques were used regarding the causes of children mortality and more complex techniques should be used such as structural equation modeling which we used to explain the interrelations among a set of variables. Mortality factor includes three indicators: standardized (infant, neonatal and stillbirth) mortality ratios, education factor includes three indicators: the percentages of population who achieved (primary, secondary and tertiary) education and prosperity factor includes three indicators: the percentages of population who classified as (CLASS13) of occupation. The data were collected from 81 districts based on the census carried out in Malaysia in 1995. Goodness of fit indexes, were examined for proposed models. Programming was used in the analysis using LISREL software. Results: It was found that p-value for the fitted models were greater than 0.05 , indicating that the proposed models are acceptable or adequate in interpreting the relationship between prosperity, education and mortality. The estimated effect of prosperity factor on mortality factor was found significant $\left(\hat{\gamma}_{11}=-0.37, \mathrm{t}\right.$-value $\left.=-3.74\right)$ but the estimated effect of education factor on mortality factor was found not significant $\left(\hat{\beta}_{12}=-0.06\right.$, $t$-value $\left.=-0.74\right)$. The proposed nested model 2 was found better than model 1 because it was more parsimonious although, $\chi_{\text {difference }}^{2}$, was not significant. Conclusion: We concluded that improvements in prosperity may automatically lead to decreasing in children mortality. So our recommendation is to enhance the level of salary and the level of occupation to decrease the problem of children mortality. Also further research is required in other developing countries taking into account other socioeconomic indicators using other techniques such as spatial analysis.
\end{abstract}

Key words: Infant, neonatal, stillbirth, mortality, education, prosperity, LISREL, MIMIC models

\section{INTRODUCTION}

Over the past half century, the link between education, health and mortality has been one of the most widely documented findings in sociological research. In spite of technical advances that have increased survival of children in developing countries, children mortality are still at least 10 times higher in developing countries than in developed countries. The enormous body of evidence shows a robust positive association between educational attainment and a variety of health outcomes (Crimmins and Saito, 2001; Feldman et al., 1989; Lynch, 2003). Although the causal relationship between education and mortality appears to be well established, its explanation is still not entirely clear. Most recent research reveals that social inequalities in babies' mortality are widening. Such findings mainly apply to countries as a whole.

Corresponding Author: Faisal G. Khamis, Department of Finance and Banking, Faculty of Economics and Administrative Sciences, Al-Zaytoonah University of Jordan, Amman, Jordan Tel.: +962795947494 
Pampalon et al. (2008) modeled the changes in the association between premature mortality (deaths occurring at an early age) and a deprivation index in four geographic settings in Québec where mortality rates are modeled using negative binomial regressions and their results showed that social inequalities in premature mortality increase everywhere in Québec except in the Montréal metropolitan area and the highest mortality rates among deprived groups are found in mid-size cities, small towns and rural areas. Relative deprivation, often measured through income inequalities, is regularly associated with higher mortality rates and lower standards of population health (Wilkinson and Pickett, 2006). For some authors, socioeconomic status operates mainly in increasing mortality through proximate risk factors such as health related behaviors (e.g., smoking and nutrition), access to health care and psychosocial processes due to relative deprivation (Adler et al., 1994; Wilkinson and Pickett, 2006). For others, social position also gives access to a wide range of useful resources for health such as money, knowledge, prestige, power and beneficial social networks (Phelan et al., 2004). Completion rates of primary school are found very dependent on household economic circumstances in rural Pakistan (Lloyd et al., 2007). Levene (2005) stated that rising levels of nutrition among mothers were translated into improved fetal viability and reduced levels of very early mortality in London in the second half of the eighteenth century. Katz et al. (2003) used regression analysis to study early infant mortality in Nepal which may help inform the design of intervention strategies. They found that some demographic and socioeconomic factors were not associated with mortality such as husband's occupation, ownership of land, house construction and household size, while the level of education for the parents has an effect on decreasing the rate of infant mortality (Pollard et al., 1974). Marchant et al. (2004) investigated the infant mortality who was born to women for whom detailed morbidity and socioeconomic data were collected during pregnancy, including hemoglobin. They found that the mortality rate of infants born to women with severe anaemia in pregnancy was three times compared to infants born to women who didn't have severe anaemia in rural Tanzania. It is a poor, rural area where there is food insecurity and delivery systems for health interventions are weak. Socioeconomic factors also played a role most likely via food insecurity. In this setting, women commonly enter pregnancy with depleted iron stores and progress to more severe degrees of anaemia.

\section{MATERIALS AND METHODS}

Data: The data are collected from the department of statistics (Dupre, 2008) based on the census of 81 districts conducted in peninsular Malaysia. We must construct on the basis of the prior concept or statistical analyses, which particular indicators load on each latent variable. More precisely, we construct the following latent variables (factors) with their respective indicators.

Mortality factor: mortality factor constructed from three indicators which are: Standardized Infant Mortality Ratio (SIMR), Standardized Neonatal Mortality Ratio (SNMR) and Standardized Stillbirth Mortality Ratio (SSMR). Infant mortality indicates the deaths under one year of age. Neonatal mortality refers to the deaths within 28 days after birth. Stillbirth occurs after 24 weeks of gestation. Standardization is a set of procedures for controlling the effects of external factors. Standardized Mortality Ratio (SMR) allows comparison of the causes of death between population groups. It is calculated as follows (Rehkopf et al., 2006):

$$
\operatorname{SMR}_{\mathrm{ij}}=\frac{\mathrm{O}_{\mathrm{ij}}}{\left(\sum_{\mathrm{j}=1}^{81} \mathrm{O}_{\mathrm{ij}} / \sum_{\mathrm{j}=1}^{81} \mathrm{~L}_{\mathrm{ij}}\right) \times \mathrm{L}_{\mathrm{ij}}}, \mathrm{i}=1,2,3 \quad \text { and } \mathrm{j}=1,2, \ldots, 81
$$

Where:

$\mathrm{SMR}_{\mathrm{ij}}=$ Standardized Mortality Ratio for ith type of mortality and jth district

$\mathrm{i} \quad=1$ for SIMR, $\mathrm{i}=2$ for SNMR and $\mathrm{i}=3$ for SSMR)

$\mathrm{O}_{\mathrm{ij}} \quad=$ Observed number of deaths

$\mathrm{L}_{\mathrm{ij}} \quad=$ Represents the number of live births for infants $(i=1)$, the number of live births for neonatals $(\mathrm{i}=2)$, while

$\mathrm{L}_{\mathrm{ij}} \quad=$ Represents the number of live births plus the number of stillbirths for stillbirths $(i=3)$

Education factor: education factor includes three indicators: Percentages of population who achieved (primary, secondary and tertiary) education. A strong public economy resulting from a high average education may allow more generosity with respect to social support and high individual incomes may trigger the establishing of some smaller private health services. Another possibility is that a higher level of education may increase the chance that the individual has a well paid job in the advanced service sector, which may offer some health advantages. Education attainment is 
associated with infant mortality. It may reflect a person's capacity to absorb new information and to act on it (Nordstrom et al., 1993). Education could influence the health of the community's infants and adults through normative behavior concerning infant care and adult cigarette smoking as well as diet (Ross and $\mathrm{Wu}, 1995)$.

Prosperity factor: Indicators of prosperity refer to the level of economic attainment of the district. These indicators described the type of occupation status for people living in the district. Three classes of occupation, starting from top to bottom in the income and social level (education), are used as follows: CLASS1 includes professional, administrative and managerial workers; CLASS2 includes clerical workers and CLASS3 includes sales and services workers. All classes are measured in percentages. Income provides necessities such as food and health care and low income status is found as one of the important factors for the people to have poorer health than those with higher income status (Hosseinpoor et al., 2005). It is important to relate health to prosperity (Townsend et al., 1988).

Analysis: Bollen (1989) argued that the latent variable approach had two advantages. First, this approach permits the integration of a range of measures or indicators of Socioeconomic Status (SES), thus avoiding the problems with choosing a single indicator. Secondly, this method allows greater control for measurement error.

Fully latent models or a Structural Equation Modeling (SEM) is an extension of standard regression models through which multivariate outcomes and latent variables can be modeled. SEM is more appropriate for this application than alternative causal modeling technique because they permit specification of "measurement models". SEM needs two types of models: The measurement model which connects the manifest variables to the latent variables and the structural model which connects latent variables between them. Slight to moderate departures from normality can be handled by the ML method (Raykov et al., 1991). In the observed variables (the indicators), there are slight departures from normality. ML estimates are quite robust to violation of normality assumption in the factor model (Bentler, 1980; Joreskog and Sorbom, 1982). The causal variable is called exogenous variable $\xi$ and the effect variable is called the endogenous variable, $\eta$. Unexplained variation is referred to as disturbance. The aim is to test the synthesized model of relations between the latent variables, where the structural equation model can be written as:

$$
\eta=\mathrm{B} \eta+\Gamma \xi+\zeta
$$

where, vectors $\eta$ and $\xi$ were not observed, instead vectors $\mathrm{y}$ and $\mathrm{x}$ were observed, such that: Measurement model for $\mathrm{y}: \mathrm{y}=\Lambda_{\mathrm{y}} \eta+\varepsilon$ and measurement model for $\mathrm{x}$ : $\mathrm{x}=\Lambda_{\mathrm{x}} \xi+\delta$.

Where mortality and education latent factors were indicated by $\eta_{1}$ and $\eta_{2}$ respectively and prosperity latent factor is indicated by $\xi_{1}$. The y vector referred to the three indicators of mortality factor and the three indicators of education factor. The $\mathrm{x}$ vector referred to the three indicators of prosperity factor. The $\mathrm{B}$ and $\mathrm{T}$ matrices are the parameters required to be estimated. The $\Lambda_{\mathrm{y}}$ and $\Lambda_{\mathrm{x}}$ are the factor loadings for $\eta$ and $\xi$. The $\varepsilon$ and $\delta$ vectors are the measurement errors for $\mathrm{y}$ and $\mathrm{x}$ respectively and $\zeta$ is referred to the disturbance. Parameter estimation was performed by Maximum Likelihood (ML) estimation. The unknown parameters of the model are estimated so as to make the variances and co-variances that are reproduced from the model in some sense close to the variances and co-variances of the observed data. Obviously, a good model would allow very close approximation to the data. The proposed models are designed specifically to answer such questions as: Is the link between mortality, prosperity and education myth or reality? From the previous studies, this link is reality in several countries but what about Malaysia?

Perhaps the most basic fit index is the likelihood ratio, which is sometimes called Chi-square $\left(\mathrm{x}^{2}\right)$ in the SEM literature. The value of the $\mathrm{x}^{2}$-statistic reflects the sample size and the value of the ML fitting function. The fitting function is the statistical criterion that ML attempts to minimize and is analogous to the least squares criterion of regression. For a particular model to be adequate, values of indexes that indicate absolute or relative proportions of the observed covariances explained by the model such as the Goodness-of-Fit Index (GFI), the Adjusted Goodness-of-Fit Index (AGFI) and Normed Fit Index (NFI) should be greater than 0.90 (Bollen, 1989; Hair et al., 1998). Comparative Fit Index (CFI) indicates the proportion in the improvement of the overall fit of the researcher's model relative to a null model like NFI but may be less affected by sample size. CFI should be greater than 0.90 (Kline, 1998) or Hu and Bentler (1999) endorsed stricter standards, pushing CFI to about 0.95. Another widely used index is the Standardized Root Mean Squared Residual (SRMR), which is a standardized summary of the average covariance residuals. Covariance residuals are the differences between the observed and model-implied co-variances. A favorable value of the SRMR is less than 0.10 ( $\mathrm{Hu}$ and Bentler, 1999). 


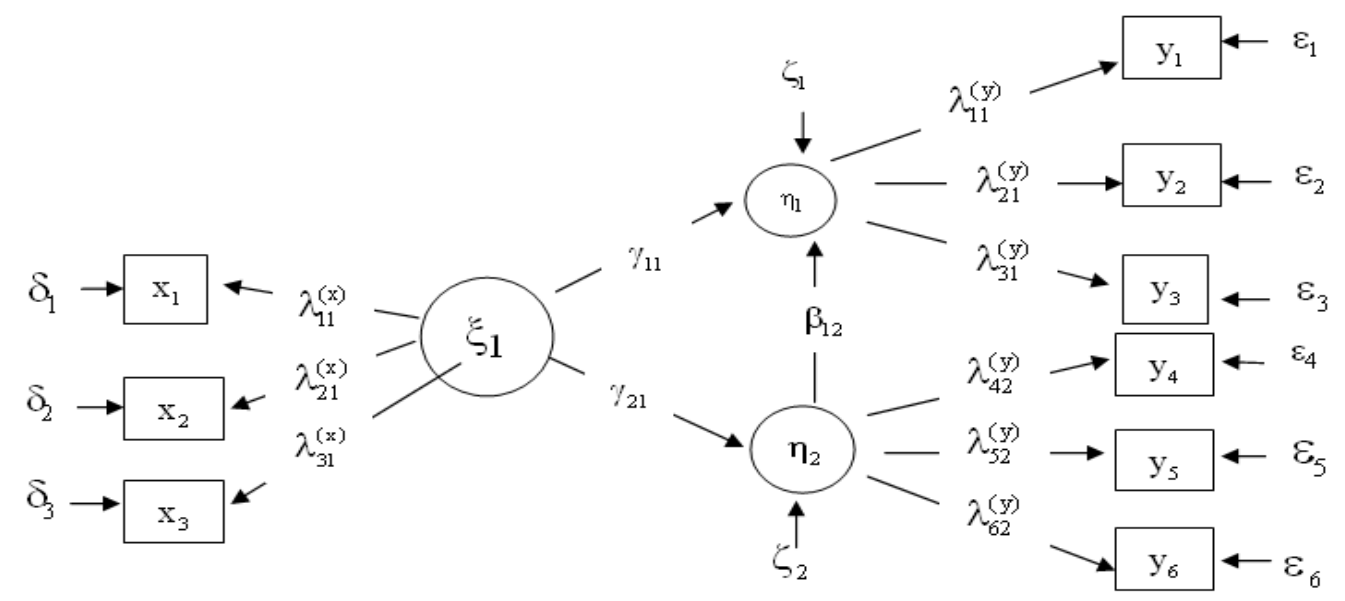

Fig. 1: Conceptualized path diagram for models 1 and 2.

Another measure based on statistical information theory is the Akaike Information Criterion (AIC). It is a comparative measure between models with different numbers of latent's. AIC values closer to zero indicate better fit and greater parsimony (Bollen, 1989; Hair et al., 1998). The Parsimonious Goodness-of-Fit Index (PGFI) modifies the GFI differently from the AGFI; where the AGFI's adjustment of the GFI is based on the degrees of freedom in the estimated and null models. The PGFI is based on the parsimony of the estimated model (Hair et al., 1998), where this index varies between 0 and 1 , with higher values indicating greater model parsimony. The Non-Normed Fit Index (NNFI) includes a correction for model complexity, much like the AGFI; a recommended value is 0.90 or greater (Hair et al., 1998). The Root Mean Square Error of Approximation (RMSEA) value below or equal to 0.08 is deemed acceptable Hair et al. (1998) and Hu and Bentler (1999) pushes RMSEA values to smaller than 0.06 and they considered it greater than 0.10 as poor fit. RMSEA is a measure to assess how well a given model approximates the true model (Bollen, 1989)

A popular way to conceptualize a model is using a path diagram, which is a schematic drawing of the model to be estimated. There are a few simple rules that assist in creating these diagrams: Ovals represent latent variables. Indicators are represented by rectangles. Directional relations are indicated using a single-headed arrow. The expression "a picture is worth a thousand words" is a very apt one for SEM. Researchers who use SEM techniques often use path-diagrams to illustrate their hypotheses and summarize the results of the analysis. Figure 1 shows a conceptualized path diagram for models 1 and 2 including all variables and parameters required to be estimated. The analysis was done using programming based on Linear Structural Relationship (LISREL) software.

\section{RESULTS}

Every application of SEM should provide at least the following information: A clear and complete specification of models and variables, including a clear listing of the indicators of each latent; a clear statement of the type of data analyzed, with presentation of the sample correlation or covariance matrix; specification of the software and method of estimation and complete results (Raykov et al., 1991). Table 1 shows Pearson correlation matrix, mean and standard deviation for each indicator. As shown in Table 2, we provided several indexes of goodness of fit, allowing for a detailed evaluation of the adequacy of the fitted models. The simplest gauge of how well the model fits the data would be to inspect the residual matrix (Field, 2000). The acceptable range of residual values is one in 20 standardized residuals exceeding \pm 2.58 strictly by chance (Hair et al., 1998). Both models have not resulted in standardized residuals exceed the threshold value and most of them were found close to zero, indicating high correspondence between elements of the implied co-variances matrix of vector $\mathrm{z}=(\mathrm{y}, \mathrm{x})$ and the sample covariance matrix. For assessing the fitted model, a model is considered adequate if the p-value is greater than 0.05 , as 0.05 significance level is recommended as the minimum acceptance level for the proposed model (Hair et al., 1998). From Table 2, it was found that $\mathrm{p}$-value for the fitted models are greater than 0.05 , indicating that the proposed models are acceptable or adequate in interpreting the relationship between prosperity, education and mortality. 
Table 1: Pearson correlation matrix, mean and Standard Deviation (SD)

\begin{tabular}{|c|c|c|c|c|c|c|c|c|c|c|c|}
\hline Variables & $\mathrm{y}_{1}$ & $\mathrm{y}_{2}$ & $\mathrm{y}_{3}$ & $\mathrm{y}_{4}$ & $\mathrm{y}_{5}$ & $\mathrm{y}_{6}$ & $\mathrm{x}_{1}$ & $\mathrm{x}_{2}$ & $\mathrm{x}_{3}$ & Mean & SD \\
\hline$\overline{\text { SIMR, } \mathrm{y}_{1}}$ & 1.00 & & & & & & & & & 1.07 & 0.28 \\
\hline SNMR, $y_{2}$ & $0.67 * *$ & 1.00 & & & & & & & & 1.03 & 0.27 \\
\hline $\mathrm{SSMR}, \mathrm{y}_{3}$ & $0.35^{* *}$ & $0.25^{*}$ & 1.00 & & & & & & & 1.07 & 0.40 \\
\hline PR_EDC, $y_{4}$ & 0.14 & $0.22 *$ & 0.03 & 1.00 & & & & & & 68.54 & 6.50 \\
\hline SE_EDC, $\mathrm{y}_{5}$ & 0.06 & 0.14 & -0.06 & $0.91 * *$ & 1.00 & & & & & 45.80 & 8.94 \\
\hline TR_EDC, $\mathrm{y}_{6}$ & 0.04 & 0.08 & -0.12 & $0.71 * *$ & $0.86^{* *}$ & 1.00 & & & & 6.17 & 3.28 \\
\hline CLÄSS1, $x_{1}$ & $-0.40^{* *}$ & -0.16 & -0.12 & -0.15 & -0.14 & -0.12 & 1.00 & & & 10.07 & 3.30 \\
\hline CLASS $2, x_{2}$ & $-0.35^{* *}$ & -0.13 & -0.25 & -0.16 & -0.14 & -0.10 & $0.88 * *$ & 1.00 & & 6.82 & 3.84 \\
\hline CLASS $3, x_{3}$ & $-0.28^{*}$ & -0.12 & -0.11 & -0.08 & -0.14 & -0.11 & 0.66 ** & $0.68 * *$ & 1.00 & 18.36 & 4.98 \\
\hline
\end{tabular}

Table 2: Comparison between the proposed models using fit indexes

\begin{tabular}{lcc}
\hline Fit-indexes & Model 1 & Model 2 \\
\hline Absolute-fit measures & & \\
$\chi^{2}$-statistic (p-value) & $29.66(0.20)$ & $30.82(0.24)$ \\
d.f & 24 & 26 \\
GFI & 0.930 & 0.920 \\
SRMR & 0.070 & 0.070 \\
RMSEA & 0.049 & 0.045 \\
Incremental-fit measures & & \\
CFI & 0.980 & 0.990 \\
AGFI & 0.860 & 0.870 \\
NFI & 0.930 & 0.920 \\
NNFI & 0.980 & 0.980 \\
Parsimonious-fit measures & & \\
PGFI & 0.490 & 0.530 \\
AIC & 70.590 & 68.160
\end{tabular}

$\chi^{2}$-statistic: Likelihood-ratio chi-square statistic, GFI: Goodness-ofFit Index, SRMR: Standardized Root Mean Square Residual, RMSEA: Root Mean Square Error of Approximation, CFI: Comparative Fit Index, AGFI: Adjusted Goodness-of-Fit Index, NFI: Normed Fit Index, NNFI: Non-Normed Fit Index (An old name for the NNFI is the Tucker-Lewis Index TLI), PGFI: Parsimonious Goodness-of-Fit Index, AIC: Akaike Information Criterion

Bollen's incremental fit-index values were examined, as these are least biased due to nonnormality of variables and they were found most of them are close to 0.95 . Figure 2 and 3 explained the estimated parameters of fitted model 1 and 2 respectively. The proposed models 1 and 2 provided an accepted fit to the observed data, where for model 1 $\left(\chi^{2}(24)=29.66, \mathrm{p}\right.$-value $\left.=0.20\right)$ and for model 2 $\left(\chi^{2}(26)=30.82, \mathrm{p}\right.$-value $\left.=0.24\right)$. The estimated effects of prosperity factor on mortality and education factors with their $\mathrm{t}$-values were shown in Table 3 . The estimated effect of education factor on mortality factor $\left(\eta_{2} \rightarrow \eta_{1}\right)$ was found not significant for both models,

Where:

$$
\left(\hat{\beta}_{12}=-0.06, \mathrm{t}=-0.74\right) \text { for model } 1
$$

and:

$$
\left(\hat{\beta}_{12}=-0.06, t=-0.69\right) \text { for model } 2
$$

Table 3: Shows the estimated parameters of all effects of latent variables with their $\mathrm{t}$-values in parentheses

\begin{tabular}{lll}
\hline Type of effect & Model 1 & Model 2 \\
\hline Direct effect & $-0.37(-3.74)$ & $-0.38(-3.67)$ \\
$\xi_{1} \rightarrow \eta_{1}, \hat{\gamma}_{11}$ & $-0.12(-1.12)$ & $-0.12(-1.12)$ \\
$\xi_{1} \rightarrow \eta_{2}, \hat{\gamma}_{21}$ & $-0.06(-0.74)$ & $-0.06(-0.69)$ \\
$\eta_{2} \rightarrow \eta_{1}, \hat{\beta}_{12}$ & & \\
Indirect effect & $0.01(0.61)$ & $0.01(0.58)$ \\
$\xi_{1} \rightarrow \eta_{2} \rightarrow \eta_{1}, \hat{\gamma}_{21} \hat{\beta}_{12}$ & $-0.36(-3.68)$ & $-0.37(-3.67)$ \\
\hline Total effect $=$ Direct, $\hat{\gamma}_{11}+$ Indirect, $\hat{\gamma}_{21} \hat{\beta}_{12}$ & & \\
\hline
\end{tabular}

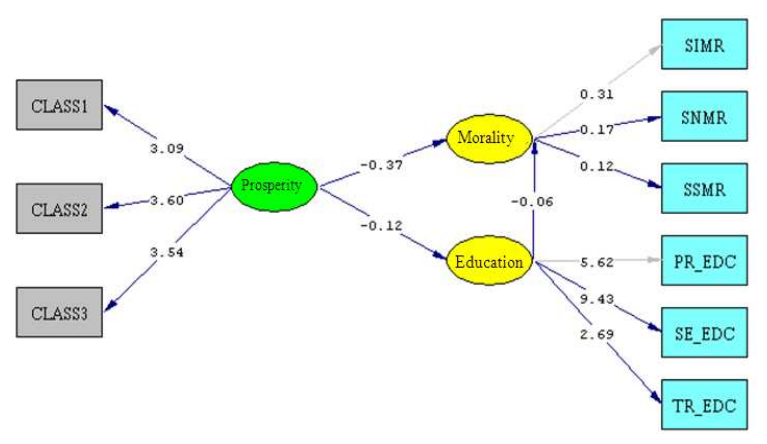

Fig. 2: Path diagram shows the results of the fitted model 1

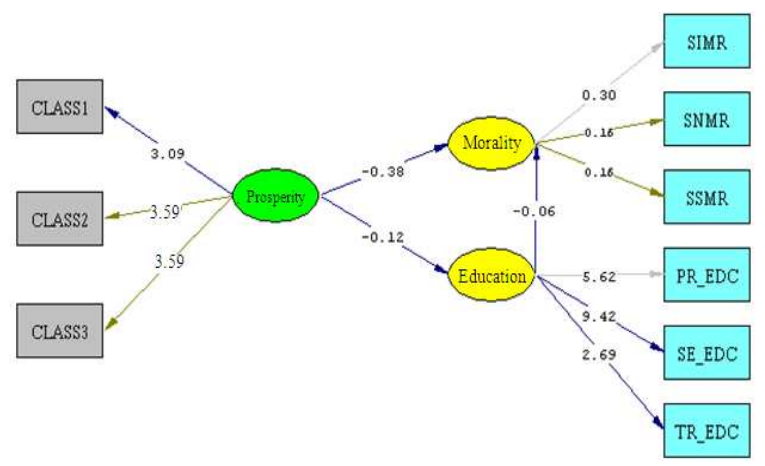

Fig. 3: Path diagram shows the results of the fitted model 2 
Figure 2 shows the factor loading of SNMR $\left(\lambda_{21}^{(y)}=0.17\right)$ closes to the factor loading of SSMR $\left(\lambda_{31}^{(y)}=0.12\right)$. Also, the factor loading of CLASS2 $\left(\lambda_{21}^{(x)}=3.60\right)$ was found close to the factor loading of CLASS3 $\left(\lambda_{31}^{(x)}=3.54\right)$. Thus, the proposed model 2 represents the same relationship as shown in model 1 but with the following constraints: The factor loadings of SNMR and SSMR are equaled $\left(\lambda_{21}^{(\mathrm{y})}=\lambda_{31}^{(\mathrm{y})}\right)$ and the factor loadings of CLASS 2 and CLASS 3 are equaled $\left(\lambda_{21}^{(x)}=\lambda_{31}^{(x)}\right)$. Models 1 and 2 were considered nested models (Bollen, 1989; Kline, 1998). The $\chi^{2}$ difference $\left(\chi_{\text {difference }}^{2}\right)$ between two nested models should be used as criterion to know which model is better than other, where $\quad\left(\chi_{\text {difference }}^{2}=30.82-29.66=1.16\right)$, which was considered not significant, with degrees freedom (22-20 $=2$ ). However, the resulted model 2 is better than model 1 because it is more parsimonious although, $\chi_{\text {difference }}^{2}$, is not significant.

\section{DISCUSSION}

Having parents with lower education may signal that the person has had special problems (resources) during childhood or adolescence, which also may have implications for later health. It was argued that other's education may affect mortality favorably through transmission of knowledge, imitation of behavior, economic support and the quality of health services. On the other hand, having better educated family members or living in a community with many better educated people, who typically also have higher incomes, may trigger psychosocial stress. Studies carried out in Canada and in USA comparing small area-based and individual measures of socioeconomic conditions along with various health outcomes, namely mortality, found social inequalities of comparable magnitude (Mustard et al., 1999; Rehkopf et al., 2006). The data we are used are called aggregated or area-level data. Small area-based measures can be used with sufficient reliability to monitor social inequalities in health (Pampalon et al., 2008). Dupre (2008) examined the relationship between education, health risks and disease onset and survival duration using Poisson regression models in US. His results suggested that education is related to both the individual and accumulated number of behavioral, social and economic health-risks, which in turn, are related to increasing educational differences in rates of disease incidence and survival. We can argue that higher education is important to make the parents more careful about any abnormal cases related to their children even if these cases were simple because sometimes the role of the time in giving the medical treatment is recommended as soon as possible. Also, perhaps these simple cases may be increase to be complicated cases which at that time the solution will be hard or even impossible. Low education attainment translates into low expected income, which in turns is the major cause of economic hardship. Economic hardship negatively impacts health (Judge and Paterson, 2001). Education is inversely related to morbidity and mortality (Manton et al., 1997). The social-psychological explanation suggests that education provides a greater sense of personal control (Mirowsky and Ross, 1998), social support (Lin and Ensel, 1989) and problem-solving abilities (Ross and Mirowsky, 1999), which promote health. Persons with low levels of education were more vulnerable to illness because they are less equipped psychologically and socially to minimize the harmful effects of stressors compared to their more educated counterparts (Rowe and Kahn, 1987; Turner et al., 1995).

\section{CONCLUSION}

With respect to model fit, researchers do not seem adequately sensitive to the fundamental reality that there is no true model and all models are wrong to some degree, even in the population and that the best one can hope for is to identify a parsimonious, substantively meaningful model that fits observed data adequately well (MacCallum and Austin, 2000). Given this perspective, it is clear that a finding of good fit does not imply that a model is correct or true, but only plausible. The education factor in Malaysia was found not associated with mortality factor based on both models. This finding is consistent with the Norwegian study (Kravdal, 2008), where Kravdal concluded that the average education in the municipality was not generally associated with mortality but beneficial effect appears among men with college education. The effect of prosperity factor on mortality factor was found highly significant based on both models. Collectively, these findings have important implications for public and policy debates. Further research is required regarding the relationship between mortality and several socioeconomic indicators such as household conditions, in other developing countries. Finally with regards to methodology, it is important to mention that we do not claim to have established the fundamental true cause of how prosperity and education affects children mortality despite the causal analysis tag. Rather, we have taken the most widely believed theories on how prosperity and education relate to mortality. 


\section{REFERENCES}

Adler, N.E., T. Boyce, M.A. Chesney, S. Cohen and S. Folkman et al., 1994. Socioeconomic status and health: The challenge of the gradient. Am. Psychol., 49: 15-24. PMID: 8122813

Bentler, P.M., 1980. Multivariate analysis with latent variables: Causal modeling. Ann. Rev. Psychol., 31: 419-456. DOI: 10.1146/annurev.ps.31.020180.002223

Bollen, K.A., 1989. Structural Equations with Latent Variables. 1st Edn., John Wiley and Sons, USA.. ISBN: 10: 0471011711, pp: 514.

Crimmins, E.M. and Y. Saito, 2001. Trends in healthy life expectancy in the United States, 1970-1990: Gender, racial and educational differences. Soc. Sci. Med., 52: 1629-1641. PMID: 11327137

Dupre, M.E., 2008. Educational differences in health risks and illness over the life course: A test of cumulative disadvantage theory. Soc. Sci. Res., 37: 1253-1266. DOI: 10.1016/J.SSRESEARCH.2008.05.007

Feldman, J.J., D.M. Makuc, J.C. Kleinman and J. Cornoni-Huntley, 1989. National trends in educational differentials in mortality. Am. J. Epidemiol., $\quad$ 129: 919-933. http://www.ncbi.nlm.nih.gov/pubmed/2705434

Field, A., 2000. Structural Equation Modeling (SEM). http://www.sussex.ac.uk/users/andyf/teaching/pg/s em.pdf

Hair, J.F., R.E. Anderson, R.L. Tatham and W.G. Black, 1998. Multivariate Data Analysis. 5th Edn., Prentice Hall, New Jersey, ISBN: 10: 0138948585, pp: 768.

Hosseinpoor, A.R., K. Mohammad, R. Majdzadeh, M. Naghavi and F. Abolhassani et al., 2005. Socioeconomic inequality in infant mortality in Iran and across its provinces. Bull. World Health Org., 83: 837-844. http://www.ncbi.nlm.nih.gov/pubmed/16302040

$\mathrm{Hu}, \mathrm{L}$. and P.M. Bentler, 1999. Cutoff criteria for fit indexes in covariance structure analysis: Conventional criteria versus new alternatives. Struct. Eq. Model., 6: 1-55. http://www.eric.ed.gov/ERICWebPortal/custom/po rtlets/recordDetails/detailmini.jsp?_nfpb=true\&_\& ERICExtSearch_SearchValue_0=EJ576570\&ERIC ExtSearch_SearchType_0=no\&accno=EJ576570

Joreskog, K.G. and D. Sorbom, 1982. Recent developments in structural equation modeling. J. Market. $\quad$ Res., 19: 404-416. http://psycnet.apa.org/?fa=main.doiLanding\&uid= 1983-07141-001
Judge, K. and I. Paterson, 2001. Poverty, income inequality and health: Treasury working paper. http://www.treasury.govt.nz/workingpapers/2001/t wp01-29.pdf

Katz, J., K.P. West Jr., S.K. Khatry, P. Christian and S.C. LeClerq et al., 2003. Risk factors for early infant mortality in Sarlahi district. Nepal Bull. World Health Org., 81: 717-725. http://www.ncbi.nlm.nih.gov/pmc/articles/PMC257 2324/

Kline, R.B., 1998. Principles and Practice of Structural Equation Modeling. 1st Edn., Guilford Press, New York, ISBN-10: 1572303379, pp: 354.

Kravdal, O., 2008. A broader perspective on education and mortality: Are we influenced by other people's education? Soc. Sci. Med., 66: 620-636. DOI: 10.1016/J.SOCSCIMED.2007.10.009

Levene, A., 2005. The estimation of mortality at the London foundling hospital, 1741-99. Populat. Stud., 59: 87-97. http://www.jstor.org/pss/30040438

Lin, N. and W.M. Ensel, 1989. Life stress and health: Stressors and resources. Am. Soc. Rev., 54: 382399. http://www.jstor.org/pss/2095612

Lloyd, C.B., C. Mete and M.J. Grant, 2007. The implications of changing educational and family circumstances for children's grade progression in rural Pakistan, 1997-2004. Econ. Educ. Rev., 28: 152-60. DOI: 10.1016/j.econedurev.2007.04.005

Lynch, S.M., 2003. Cohort and life-course patterns in the relationship between education and health: A hierarchical approach. Demography, 40: 309-331. http://www.ncbi.nlm.nih.gov/pubmed/12846134

MacCallum, R.C. and J.T. Austin, 2000. Applications of structural equations modeling in psychological research. Ann. Rev. Psychol. Res. Ann. Rev. Psychol., 51: 201-226. DOI:10.1146/annurev.psych.51.1.201

Manton, K.G., E. Stallard and L. Corder, 1997. Education-specific estimates of life expectancy and age-specific disability in the US elderly population. J. Aging Health, 9: 419-450. http://www.ncbi.nlm.nih.gov/pubmed/10182387

Marchant, T., J.A. Schellenberg, R. Nathan, S. Abdulla and O. Mukasa et al., 2004. Anaemia in pregnancy and infant mortality in Tanzania. Trop. Med. Int. Health, $\quad$ 9: 262-266. http://www.ncbi.nlm.nih.gov/pubmed/15040564

Mirowsky, J. and C.E. Ross, 1998. Education, personal control, lifestyle and health: A human capital hypothesis. Res. Aging., 20: 415-449. DOI: 10.1177/0164027598204003 
Mustard, C.A., S. Derksen, J.M. Berthelot and M. Wolfson, 1999. Assessing ecologic proxies for household income: A comparison of household and neighborhood level income measures in the study of population health status. Health Place, 5: 157171. DOI: 10.1016/S1353-8292(99)00008-8

Nordstrom, M.L., S. Cnattingius and B. Haglund, 1993. Social differences in Swedish infant mortality by cause of death, 1983-1986. Am. J. Pub. Health, 83:

26-30. http://ajph.aphapublications.org/cgi/content/abstrac $\mathrm{t} / 83 / 1 / 26$

Pampalon, R., D. Hamel and P. Gamache, 2008. Recent changes in the geography of social disparities in premature mortality in Québec. Soc. Sci. Med., 67: 1269-1281.

http://cat.inist.fr/?aModele $=$ afficheN\&cpsidt $=2067$ 5913

Phelan, J.C., B.G. Link, A. Diez-Roux, I. Kawachi and B. Levin, 2004. Fundamental causes of social inequalities in mortality: A test of the theory. J. Health Soc. Behav., 45: 265-285. http://www.ncbi.nlm.nih.gov/pubmed/15595507

Pollard, A.H., F. Yusuf and G.N. Pollard, 1974. Demographic Techniques. 1st Edn., Pergamon Press, Australia, ISBN: 0080173780, pp: 161.

Raykov, T., A. Tomer and J.R. Nesselroade, 1991. Reporting structural equation modeling results in psychology and aging: Some proposed guidelines. Psychol. Aging, 6: 499-503. http://www.ncbi.nlm.nih.gov/pubmed/1777136
Rehkopf, D.H., L.T. Haughton, P.D. Waterman, S.V. Subramanian and N. Krieger, 2006. Monitoring socioeconomic disparities in death: Comparing individual-level education and areabased socioeconomic measures. Am. J. Publ. Health, 96: 2135-2138. DOI: 10.2105/AJPH.2005.075408

Ross, C.E. and C.L. Wu, 1995. The links between education and health. Am. Soc. Rev., 60: 719-745. http://www.jstor.org/pss/2096319

Ross, C.E. and J. Mirowsky, 1999. Refining the association between education and health: The effects of quantity, credential and selectivity. Demography, 36: 445-460. http://www.ncbi.nlm.nih.gov/pubmed/10604074

Rowe, J.W. and R.L. Kahn, 1987. Human aging: Usual and successful. Science, 237: 143-149. DOI: 10.1126/science. 3299702

Townsend, P., P. Phillimore and A. Beattie, 1988. Health and Deprivation: Inequality and the North. 1st Edn., Routledge, London, ISBN: 0709943512, pp: 211.

Turner, R.J., B. Wheaton and D.A. Lioyd, 1995. The epidemiology of social stress. Am. Soc. Rev., 60: 104-125. http://www.jstor.org/pss/2096348

Wilkinson, R.G. and K.E. Pickett, 2006. Income inequality and population health: A review and explanation of the evidence. Soc. Sci. Med., 62: 1768-1784.

http://www.ncbi.nlm.nih.gov/pubmed/16226363 